crystallized as the bromates without having been separated into the cerium and yttrium groups. The insoluble end of the bromate series will contain only europium, samarium, gadolinium and neodymium. These fractions may be converted to the dimethyl phosphates and fractionated. The gadolinium should be easily obtained very pure from the least soluble fractions. Precipitation with sodium glycolate may take the place of the dimethyl phosphate fractionation or may be employed for the removal of the last traces of samarium remaining in the gadolinium from the dimethyl phosphate series.

URBANA, ILL.

[Contribution from the Laboratory of Qualitative Analysis, College of the City OF NEW YoRK aNd THE HaRRIMAN RESEARCh IABORATORY, ROOSEVEIT HOSPITAL, NEW YORK.]

\title{
A STUDY OF THE TEST FOR TARTRATES DEPENDING UPON THE FORMATION OF THE COPPER-TARTRATE COMPLEX.
}

By L. J. Curtuan, A. Lewis and B. R. Harris.

Received August 25, 1917.

The test described by Böttger, ${ }^{1}$ depending upon the solubility of cupric hydroxide in alkaline solutions of alkali tartrates, appears to offer a simple and reliable means for the detection of tartrates. But it was observed in preliminary experiments, the object of which was a systematic procedure for the identification of tartrates, that in actual practice, the formation of the copper-tartrate ion was affected by a number of variables which could not be predicted from a theoretical consideration of the reaction. It became apparent, moreover, that the influence of these variables was of such importance that it would be necessary to make a thorough study of certain phases of the reaction before it could be safely used in systematic analysis.

The first aim was to determine the sensitiveness of the test under a set of definitely specified conditions.

Procedure I.-A definite volume of a standard potassium tartrate ${ }^{2}$ solution was measured into a small beaker. I.5 cc. $^{3}$ of $10 \%$ sodium hydroxide and I cc. of $0.5 \mathrm{~N}$ copper sulfate were added. The mixture was stirred thoroughly one minute and transferred to a filter. The filtrate, received in a test tube was treated with strong ammonium hydroxide in excess. The results are given in Table $\mathrm{I}$.

The coloration obtained with I mg. was detectable only by very close comparison with the blank.

1 "The Principles of Qualitative Analysis," Smeaton's translation, 1906, 159.

${ }^{1} \mathrm{~K}_{2} \mathrm{C}_{4} \mathrm{H}_{4} \mathrm{O}_{6} .{ }^{1} /{ }_{2} \mathrm{H}_{2} \mathrm{O}$ was used.

2 Experiment showed that this amount of sodium hydroxide provided a safe excess over that required to completely precipitate the quantity of copper used. 


\begin{tabular}{|c|c|c|}
\hline No. & $\begin{array}{c}\mathrm{C}_{4} \mathrm{H}_{4} \mathrm{O}_{8} . \\
\mathrm{Mg} .\end{array}$ & $\begin{array}{c}\text { TABLE I. } \\
\text { Result. }\end{array}$ \\
\hline $\mathbf{I}-6$ & $50-10$ & Deep blue coloration \\
\hline $7-9$ & $5-3$ & Fair blue coloration \\
\hline Io & 2.5 & Faint blue coloration \\
\hline II -14 & $2.0-1.5$ & Very faint blue coloration \\
\hline $15-17$ & I.O & Exceedingly faint blue coloration (limit) \\
\hline I8 & 0.0 & Colorless \\
\hline
\end{tabular}

Another set of experiments indicated that by acidifying the filtrate with $25 \%$ acetic acid and treating with one drop of $N$ potassium ferrocyanide, the sensitiveness could be considerably improved. $0.2 \mathrm{mg}$. was detectable by this procedure.

To ascertain the effect of time on the reaction, $0.5 \mathrm{mg} . \mathrm{C}_{4} \mathrm{H}_{4} \mathrm{O}_{6}$ was treated by the procedure described above, modified in one respect: namely, in successive experiments; the solution, after being stirred, was allowed to stand for a gradually increasing time noted in the first column of Table II.

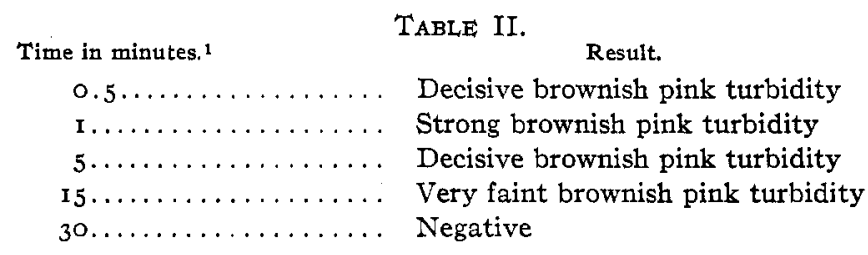

The above data led to the conclusion that the postponement of the filtration after stirring had a prejudicial effect on the sensitiveness of the reaction. Furthermore, it is evident that one minute is approximately the optimum time.

That heating would be detrimenta ${ }^{2}$ was expected, but it was thought desirable to obtain data which would demonstrate this point.

Increasing quantities of tartrate were treated by the procedure described; after being stirred one minute the solution was heated until all blue cupric hydroxide had disappeared. The copper oxide was then filtered and the filtrate treated as above. Table III gives the results.

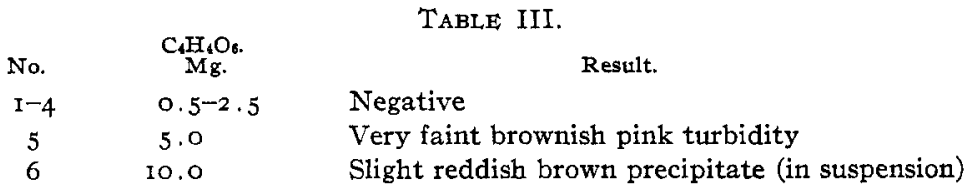

The test given by Io $\mathrm{mg}$. tartrate in Table III corresponded roughly to that obtained with I mg. treated in the cold. Obviously, then, heating is undesirable.

1 To be exact it should be stated that the interval recorded is the time which elapsed between the addition of the copper solution and the filtration.

2 Böttger, Loc. cit. 
The procedure which would suggest itself, in view of the information given above, would apparently be satisfactory, giving, as it does, a sensitiveness of $0.2 \mathrm{mg}$. tartrate. But upon further consideration, and particularly in consequence of the information given in Table IV, below, it becomes evident that the procedure is eminently defective in one respect; ${ }^{1}$ it does not furnish (or at least only within very narrow limits) the means by which may be made a rough estimate of the amount of tartrate present.

This observation suggested the necessity of determining directly the quantity of copper, as copper hydroxide, which would be dissolved by the maximum amount of tartrate which might ordinarily be expected. 500 mg. were considered a reasonable figure.

Procedure II. ${ }^{2}-500 \mathrm{mg}$. tartrate were treated in a Ioo cc. beaker with sodium hydroxide; the mixture was diluted to about $5 \mathrm{cc}$., copper sulfate was added and the mixture stirred vigorously for one minute; it was then poured on the filter, the filter was washed thoroughly and examined for a residue of cupric hydroxide.

A parallel set of blanks were run without tartrate. In these experiments, the filtrates caught in test tubes, were acidified with acetic acid and tested with potassium ferrocyanide, the object being to see whether, in each case, the sodium hydroxide used was sufficient to precipitate all the copper present.

The experiments are recorded in Table IV.

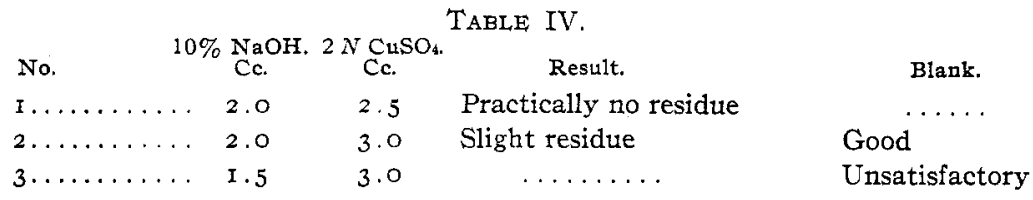

Several inferences may be made from the above table: (I) 3 cc. $2 \mathrm{~N}$ copper sulfate may be relied upon to take care of $500 \mathrm{mg}$. of tartrate; (2) approximately $2 \mathrm{cc}$. of $10 \%$ sodium hydroxide are required to insure the precipitation of that amount of copper; (3) the proportion of tartrate to copper in the reaction, under the conditions specified, is approximately $500: 160 .^{3}$

It seemed, therefore, that No. 2, Table IV, furnished the suitable proportions of copper and alkali. However, when I mg. tartrate was treated with $2 \mathrm{cc}$. of $10 \%$ sodium hydroxide and $3 \mathrm{cc}$. of $2 \mathrm{~N}$ copper sul-

${ }^{1}$ Besides, a subsequent, rigorous test of the method by several individuals showed that the blanks and the reactions with small amounts of tartrate were not uniformly good.

${ }^{2}$ A filter and a test tube for the filtrate were prepared beforehand so that no time should elapse between the cessation of stirring and the filtration.

3 That this is the case may be seen from the following calculation: I ce. $2 \mathrm{~N}$ $\mathrm{CuSO}_{4}=0=63 \mathrm{mg}$. Cu, $2.5 \mathrm{cc}$., therefore contain about I60 mg. Cu. 
fate, no copper was found in the filtrate, $i . e$., a negative test for tartrate was obtained.

This experiment indicated that in all probability an excess of sodium hydroxide was required for the reaction.

Procedure III. - A series of experiments was made in which $0.5 \mathrm{mg}$. tartrate was treated with $3 \mathrm{cc} .2 N$ copper sulfate and with increasing amounts of sodium hydroxide with I minute's stirring. ${ }^{1}$ The mixture was filtered, washed with sufficient water to give a filtrate of $7 \mathrm{cc}$; the filtrate and washings, caught in a test tube, were acidified ${ }^{2}$ with $50 \%$ acetic acid, treated with 2 cc. of $26 \%$ potassium ferrocyanide, ${ }^{3}$ diluted, if necessary, to ro cc., shaken, allowed to stand I minute and observed.

The procedure in which $2.5 \mathrm{cc}$. of $25 \%$ sodium hydroxide were used, was found to give the most satisfactory results. But, in spite of the fact that the method was sensitive to I mig. and was capable of giving quantitative indications up to $500 \mathrm{mg}$., it was found necessary, nevertheless, to abandon it for a variety of reasons. A blank was not obtainable unless special care was taken to add the $2 \mathrm{cc}$. of ferrocyanide at once. If one drop was first added, it was impossible to obtain a negative result. Furthermore, I or even $2 \mathrm{mg}$. tartrate did not give satisfactorily uniform results. At certain times strong and at other times very faint reactions were obtained.

It was thought that these discrepancies might have been due to differences in the speed of filtration owing to differences in individual funnels. Filtering by suction was, therefore, tried, but offered no advantage.

Another possible cause for the lack of uniformity, it was conjectured might have been due to differences in the rapidity and thoroughness of stirring. The experiments were, therefore repeated in test tubes, stoppered with rubber stoppers, ${ }^{4}$ with shaking substituted for stirring. The uniformity in the blanks then became satisfactory but I or $2 \mathrm{mg}$. still failed to give concordant results.

Numerous procedures were then tested in which the amount of copper was kept constant (the amount required for $500 \mathrm{mg}$. of tartrate) but in which the quantity of sodium hydroxide and the volume in which the precipitation was made were varied within wide limits. No satisfactory method could be devised. In general, these experiments led to the conclusion that when the quality of the blanks improved, the sensitiveness of the test suffered and vice versa.

From the experience gained it was considered advisable to concen-

1 A filter and test tube were prepared beforehand.

2 In testing for acidity, care must be taken not to introduce any litmus into the test tube. Its pink color vitiates the test.

3 Calculation showed that this quantity of ferrocyanide was sufficient to precipitate all the copper which would appear in the filtrate in the presence of $500 \mathrm{mg} . \mathrm{C}_{4} \mathrm{H}_{4} \mathrm{O}_{6}$.

4 The stoppers were cleaned by soaking in lye. 
trate on a trustworthy qualitative procedure and to temporarily abandon the idea of devising a method which would give an absolutely reliable qualitative test and would, at the same time, furnish quantitative indications. With this aim in view, the alkali and copper were materially reduced and Procedure IV was eventually developed.

Procedure IV. $-3 \mathrm{cc}$. of $2.5 \% \mathrm{NaOH}$ were added to a test tube containing approximately $5 \mathrm{cc}$. of the neutral or faintly alkaline solution to be tested. The solution was then treated with I cc. $0.2 \mathrm{~N}$ copper sulfate and enough water was added to make the volume $10 \mathrm{cc}$. The test tube was then stoppered with a rubber stopper and was shaken vigorously for I minute and filtered. ${ }^{1}$ The clear filtrate was acidified with $50 \%$ acetic acid, treated with I drop of $N$ potassium ferrocyanide, set aside for $\mathrm{I}$ minute and observed.

Table $\mathrm{V}$, showing the behavior of various amounts of tartrate is given below. The filter paper was also examined for a residue of cupric hydroxide with the aim of determining approximately the maximum amount of tartrate which the quantity of copper used in the experiment was able to take care of.

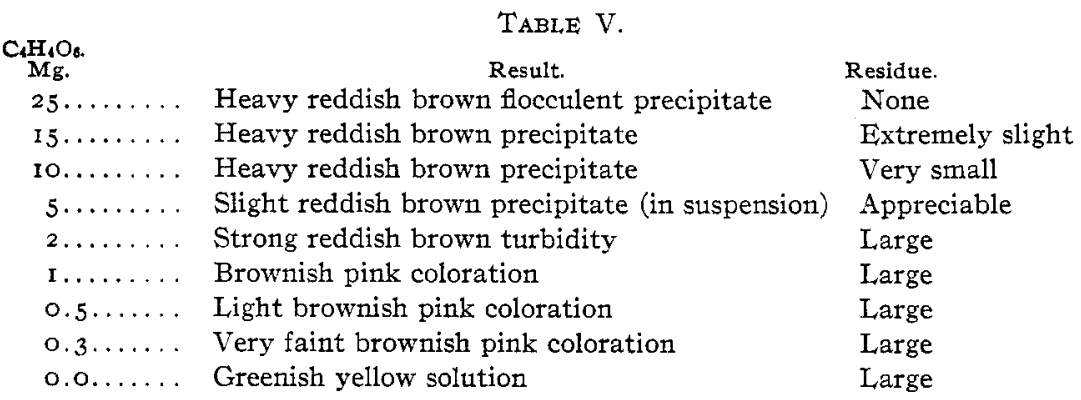

With experience, $0.3 \mathrm{mg}$. tartrate may be detected, especially by looking down the tube. $0.5 \mathrm{mg}$., however, gives invariably an unmistakable brownish pink coloration. This is the practical limit of the test and the point at which no reasonable doubt can be entertained as to the presence of tartrates.

The "Residue" column indicates that ${ }_{5} \mathrm{mg}$. is approximately the quantitative limit, $i . e$., all quantities of tartrate above that will give tests of the same intensity.

It was expected that ammonium salts and arsenites ${ }^{2}$ would respond to this test for tartrates. Experiments showed that $4 \mathrm{mg}$. arsenite and 3 to $5 \mathrm{mg}$. ammonium were the minimum quantities which, in the procedure last described, gave an appreciable brownish pink coloration. Larger quantities gave proportionately stronger tests.

1 The filtrate generally appeared turbid and was refiltered (on the original filter) till it was perfectly clear. As a rule, one or two refiltrations sufficed.

2 Roscoe and Schorlemmer, Vol. II, Part I (1879), 34I; Böttger, Loc. cit. 


\begin{tabular}{|c|c|}
\hline \multirow{2}{*}{\multicolumn{2}{|c|}{ No. Acid. }} \\
\hline & $\mathrm{CO}_{3}$ \\
\hline 2 & $\mathrm{CO}_{3}$ \\
\hline 3 & $\mathrm{SO}_{3}$ \\
\hline 4 & $\mathrm{SO}_{3}$ \\
\hline $5-7$ & $\mathrm{~S}_{2} \mathrm{O}_{3}$ \\
\hline 8-9 & $\mathrm{S}_{2} \mathrm{O}_{3}$ \\
\hline IO & $\mathrm{SO}_{4}$ \\
\hline I I & $\mathrm{SO}_{4}$ \\
\hline I $2-I 3$ & $\mathrm{PO}_{4}$ \\
\hline I 4 & $\mathrm{PO}_{4}$ \\
\hline I5-I 6 & $\mathrm{C}_{2} \mathrm{O}_{4}$ \\
\hline $17-20$ & $\mathrm{C}_{2} \mathrm{O}_{4}$ \\
\hline $2 I-23$ & $\mathrm{~B}_{4} \mathrm{O}_{7}$ \\
\hline $24-25$ & $\mathrm{~B}_{4} \mathrm{O}_{7}$ \\
\hline 26 & $\mathrm{~B}_{4} \mathrm{O}_{7}$ \\
\hline $27-3 I$ & $\mathrm{AsO}_{4}$ \\
\hline $32-33$ & $\mathrm{AsO}_{4}$ \\
\hline 34 & $\mathrm{AsO}_{4}$ \\
\hline 35 & $\mathrm{CrO}_{4}$ \\
\hline $36-37$ & $\mathrm{CrO}_{4}$ \\
\hline 38 & $\mathrm{~F}$ \\
\hline 39 & $F$ \\
\hline 40 & $\mathrm{~F}$ \\
\hline $4 \mathrm{I}$ & $\mathrm{Cl}$ \\
\hline $4^{2}$ & $\mathrm{Cl}$ \\
\hline 43 & $\mathrm{Br}$ \\
\hline 44 & $\mathrm{Br}$ \\
\hline 45 & I \\
\hline 46 & $5 \mathrm{I}$ \\
\hline 47 & $\mathrm{CN}$ \\
\hline $4^{8}$ & $\mathrm{SCN}$ \\
\hline 49 & $\mathrm{SCN}$ \\
\hline 50 & $\mathrm{Fe}(\mathrm{CN})_{6} \mathrm{II}$ \\
\hline $5 \mathrm{I}-52$ & ${ }^{2} \mathrm{Fe}(\mathrm{CN})_{{ }^{\mathrm{T}}} \mathrm{T}$ \\
\hline $\begin{array}{r}53 \\
54-56\end{array}$ & $\begin{array}{l}3 \mathrm{Fe}(\mathrm{CN})_{\theta^{\mathrm{IV}}} \\
\mathrm{Fe}(\mathrm{CN})_{6} \mathrm{IV}\end{array}$ \\
\hline
\end{tabular}

$57 \mathrm{NO}_{2}$

$58-59 \mathrm{NO}_{2}$

$60 \mathrm{NO}_{3}$

6I $\mathrm{NO}_{8}$.

$62 \mathrm{C}_{2} \mathrm{H}_{3} \mathrm{O}_{2}$

$63 \mathrm{C}_{2} \mathrm{H}_{3} \mathrm{O}_{2}$

$64 \mathrm{C}_{2} \mathrm{H}_{3} \mathrm{O}_{2}$

$65 \mathrm{ClO}_{3}$

$66 \mathrm{ClO}_{3}$
TABle VI.-Test ANalyses.

\section{$\mathrm{C}_{4} \mathrm{H}_{4} \mathrm{O}_{8.1}$}

$\overbrace{0.0 \mathrm{mg} .} 1.0 \mathrm{mg}$. Results.

$500 \quad$ Faint greenish yellow solution (negative)

500 Brownish pink coloration-light (positive)

$500 \quad$ Faint greenish yellow solution (negative)

500 Exceedingly faint pink solution (positive)

$500 \quad$ Faint greenish yellow solution (regative)

500-250 Faint greenish yellow solution (negative)

$500 \quad$ Faint greenish yellow solution (negative)

500 Light brownish pink coloration (positive)

500-250 Heavy brownish red immediate precipitate (pos.)

5o Faint brownish pink turbidity (positive)

500-250 Very faint greenish yellow solution (negative)

$\begin{array}{ll}500-250 & \text { Faint greenish yellow solution (negative) } \\ 500-250 & \text { Heavy brownish red immediate precipitate (pos.) }\end{array}$

r5o Strong brownish pink coloration (positive)

I00 Faint greenish yellow solution (negative)

$500 \quad$ Faint greenish yellow solution (negative)

500 Faint greenish yellow solution (negative)

250 Strong brownish pink turbidity (positive)

$500 \quad$ Orange-red solution perfectly clear (negative)

500-250 Orange-red solution (test masked by color)

$500 \quad$ Faint greenish yellow solution (negative)

500 Faint greenish yellow solution (negative)

250 Light brownish pink coloration (positive)

$500 \quad$ Faint greenish yellow solution (negative)

500 Light brownish pink turbidity (positive)

$500 \quad$ Faint greenish yellow solution (negative)

500 Light brownish pink coloration (positive)

$500 \quad$ Pale greenish yellow solution (negative)

500 Light brownish pink coloration (positive)

$500 \quad$ Colorless solution, perfectly clear

$500 \quad$ Faint yellow solution (negative)

500-250 Greenish yellow solution (negative)

$500 \quad$ Dark yellow solution (negative)

500-250 Dark brownish yellow solution (color masks test)

$500 \quad$ Strong yellow solution (negative)

500-250 Strong brownish yellow solution (color masks test)

500 Dark brownish yellow solution (liberated oxides of $\mathrm{N}$ )

500-250 Dark brownish yellow solution (color masks test)

$500 \quad$ Faint greenish yellow solution (negative)

500 Light brownish pink coloration (positive)

Faint greenish yellow solution (negative)

500

500 Very faint greenish yellow solution (negative)

250 Light brownish pink coloration (positive)

Very faint greenish yellow solution (negative)

500 Light pink coloration (positive)

1 The first column under this heading gives the quantities of the several acid radicals used in the controls; the second column gives the amounts of each acid radical present together with one $\mathrm{mg}$. of tartrate. 
To find the value of the procedure for the detection of tartrates in the presence of other acids, numerous test analyses were made by Procedure IV. The results are recorded in Table VI.

Comments on the Test Analyses.--(I) $250 \mathrm{mg}$. either of borate or phosphate gave strong tests in the absence of tartrates. The copper, in these cases, was easily visible in the filtrates even before the addition of ferrocyanide. As little as $50 \mathrm{mg}$. of phosphate or $5_{50}$ of borate gave decisive positive tests in the absence of tartrates. In view of the fact that no record of such a property of borates or phosphates could be found in the literature, it was thought desirable to repeat the experiments by Böttger's ${ }^{1}$ procedure; $100 \mathrm{mg}$. phosphate and I 50 of borate gave decidedly positive tests. ${ }^{2}$

(2) Chromates, ferricyanides and ferrocyanides contributed colors to the final filtrates which masked the brownish pink brought about by I $\mathrm{mg}$. of tartrate.

(3) Cyanides caused copper to appear in the filtrate as alkali cuprocyanide.

(4) In the presence of $500 \mathrm{mg}$. thiosulfate, fluoride, acetate, arsenate, thiocyanate or nitrite, negative results were obtained with I ing. tartrate. Even $250 \mathrm{mg}$. of thiosulfate, nitrite, thiocyanate interfered with the detection of I mg. of tartrate.

(5) In the case of thiosulfate or nitrite, it was surmised that the acidification with acetic acid might have been the cause of the interference by reason of the sulfur dioxide or oxides of nitrogen liberated. The experiments were, therefore, repeated and ammonium hydroxide was used as the reagent for copper. Negative tests were still obtained for I $\mathrm{mg}$. tartrate as before.

A series of experiments was also run with certain typical organic substances. $25 \mathrm{mg}$. each of glucose, lactose, dextrin, starch, glycerine, glycine, leucine, sodium salicylate, aspartic and citric acids were separately treated by Procedure VI. All gave decidedly positive tests of varying intensities.

\section{Summary and Conclusions.}

(I) The test for tartrates based on the formation of a soluble copper complex has been submitted to an experimental study.

(2) Data are supplied showing that the test can be rendered more sensitive by employing the ferrocyanide reagent for the ultimate testing of copper instead of ammonia. Also that heating the reaction mixture as well as extending the time before filtration are undesirable.

(3) It has been demonstrated that $500 \mathrm{mg}$. of tartrate dissolve approxi-

${ }^{1}$ Loc. cit.

${ }^{2}$ It was suspected that the phosphate and borate used might have contained sufficient ammonium, as an impurity, to give the reaction. Suitable tests showed the absence of ammonium. 
mately $\mathrm{I} 60 \mathrm{mg}$. of copper as $\mathrm{Cu}(\mathrm{OH})_{2}$ and that, therefore, a procedure employing less than this quantity of copper cannot afford quantitative indications for amounts up to $500 \mathrm{mg}$. of tartrate.

(4) A procedure capable of taking care of $500 \mathrm{mg}$. tartrate has been suggested and attention has been called to the difficulties which the use of this procedure entails.

(5) Based on the data obtained in this study, a purely qualitative procedure has been devised which is shown to be sensitive to $0.2 \mathrm{mg}$. tartrate. In consequence, however, of the amount of copper employed, this procedure is capable of supplying quantitative indications only within narrow limits.

(6) Numerous test analyses by this procedure showed that:

(a) Rather small amounts of ammonium, arsenite, borate, and phosphate give the test.

(b) The colors of chromates, ferrocyanides and ferricyanides mask the test color.

(c) Cyanides dissolve the copper hydroxide.

(d) One mg. of tartrate gives a negative test in the presence of $500 \mathrm{mg}$. of any of the following radicals: thiosulfate, arsenate, chromate, fluoride, thiocyanate, nitrite or acetate, or in the presence of $250 \mathrm{mg}$. of the following radicals: thiosulfate, oxalate, thiocyanate or nitrite.

(7) A great variety of organic substances give the same test.

New YoRk CITY.

[CONTRIBUTion FROM THE DEPARTMENT OF Chemistry, University OF Wisconsin.]

\section{THE SOLUBILITY OF SILICA.}

By Victor Lenher and Henty Baldwin Merrili.

Received October 1, 1917.

While we commonly regard silica as one of our most insoluble substances, yet it has long been realized that silica, even in the form of quartz, is somewhat soluble in water and in dilute acids. The quantitative determination of silica has been known for a long time to be in error, due to the solvent action of dilute hydrochloric acid, and various procedures have been worked out to minimize these losses. ${ }^{1}$

Various workers have given data of widely different character on the solubility of silica. Fuchs ${ }^{2}$ digested gelatinous silica with acid cold or hot, filtered the resulting solution through a double filter and determined the silica in $50 \mathrm{~g}$. of the filtrate. He found water at the room temperature to dissolve $0.13 \mathrm{~g}$. $\mathrm{SiO}_{2}$ per liter, hydrochloric acid (sp. gr. I.II5) to dissolve $0.09 \mathrm{~g}$. $\mathrm{SiO}_{2}$ at room temperature, and $0.18 \mathrm{~g}$. $\mathrm{SiO}_{2}$ per liter at the

1 Bunsen, Ann., 6r, 265; Ludwig, Zeit. anal. Chem., 9, 32; Meinike, Repert. Anal. Chem., 7, 215, 757; Cameron, Chem. News, 69, 171; Hillebrand, This Journal, 24, 362; Lenher and Truog, Ibid., 36, 1050.

2 Fuchs, Ann., 82, I 19. 